\title{
BO-related Defects: Overcoming Bulk Lifetime Degradation in crystalline Si by Regeneration
}

\author{
Giso Hahn ${ }^{\mathrm{a}}$, Svenja Wilking ${ }^{\mathrm{b}}$, and Axel Herguth ${ }^{\mathrm{c}}$ \\ University of Konstanz, Department of Physics, 78457 Konstanz, Germany \\ agiso.hahn@uni-konstanz.de, bsvenja.wilking@uni-konstanz.de, caxel.herguth@uni-konstanz.de
}

Keywords: crystalline $\mathrm{Si}$, solar cell, boron-oxygen, defect, regeneration, hydrogen

\begin{abstract}
Boron-oxygen related defects formed under working conditions of a c-Si solar cell can be a showstopper for new cell concepts enabling higher conversion efficiencies. The recombination activity of these defects can be reduced to negligible values by a regeneration process under elevated temperatures and in the presence of excess charge carriers in the Si bulk. It is shown that this process also relies on the presence of $\mathrm{H}$ in the c-Si bulk. Regeneration kinetics can be sped up by higher temperatures, higher concentrations of excess charge carriers and higher $\mathrm{H}$ concentration in the c-Si bulk. But care has to be taken to avoid a destabilization reaction taking place at higher temperature, resulting in the BO-related defects being again present in the recombination-active state. A 3-state model with the corresponding reaction rates between the different defects states describes the experimental findings and can be used for predictions of an optimized regeneration process.
\end{abstract}

\section{Introduction}

Indications towards a boron-oxygen(BO)-related degradation were first published in 1973 [1]. This effect can severely limit minority charge carrier bulk lifetime $\tau_{\mathrm{b}}$ in O- and B-rich crystalline Si (c-Si) materials like p-type monocrystalline Czochralski(Cz) grown $\mathrm{Si}$ upon illumination. It scales linearly with $\mathrm{B}$ concentration $[\mathrm{B}][2,3]$ and almost quadratically with interstitial $\mathrm{O}$ concentration $\left[\mathrm{O}_{\mathrm{i}}\right]$ [4]. Depending on [B] and [ $\left.\mathrm{O}_{\mathrm{i}}\right]$ a so-called fundamental lifetime limit can be calculated [5], resulting in values of $\tau_{\mathrm{b}} \sim 20-40 \mu \mathrm{s}$ for $1 \Omega \mathrm{cm} \mathrm{Cz}$ material with typical $\left[\mathrm{O}_{\mathrm{i}}\right]$ of $6-8 \cdot 10^{17} \mathrm{~cm}^{-3}$. This reduction in $\tau_{\mathrm{b}}$ severely affects stable conversion efficiency $\eta$ of state-of-the-art solar cells and limits $\eta$ to values $\sim 19 \%$ for $\mathrm{p}$-type $\mathrm{Cz}-\mathrm{Si}$ solar cells with full Al back surface field (BSF) technology.

Currently, a new generation of c-Si solar cell architecture is entering industrial mass production, the passivated emitter and rear cell (PERC) concept. In these solar cells, recombination at the rear side is significantly reduced by use of a surface passivating dielectric layer (stack) and only local metal contacts to the base of the solar cell. With this technology, higher efficiencies $>21 \%$ can be reached immediately after cell fabrication on large area p-type $\mathrm{Cz}-\mathrm{Si}$. But upon illumination, the formation of BO-related defects limits $\eta$ to values $<20 \%$ on $1 \Omega \mathrm{cm}$ material. Therefore, strategies to avoid the severe degradation due to BO-related defects are necessary to exploit the full potential of B doped p-type Cz-Si solar cells.

Conventional measures taken to deal with BO-related degradation are:

- reducing $\left[\mathrm{O}_{\mathrm{i}}\right]$ in $\mathrm{Cz}-\mathrm{Si}$, e.g. by making use of magnetic fields during crystal growth (resulting in higher costs)

- replace B by Ga (taking into account that the segregation coefficient of $\mathrm{Ga}$ is «1, resulting in inhomogeneous doping concentration along the ingot height)

- avoid use of p-type wafers and use (e.g. P-doped) n-type wafers instead (generally leading to more complex solar cell processing and therefore higher costs)

- reduce [B] by using 2-5 $\Omega \mathrm{cm}$ material (increasing ohmic losses especially for PERC-type solar cells due to the lateral movement of majority carriers to the local back contact).

As all measures mentioned above have disadvantages, no industrial solution has been found yet. 


\section{Regeneration of BO-related Defects}

The degradation of BO-related defects under illumination shows temperature-dependent kinetics following the Arrhenius law and cannot be sped up with stronger illumination levels as kinetics saturates at illumination levels of $\sim 0.01$ suns [6]. The degradation is totally reversible by annealing in the dark at $\sim 200^{\circ} \mathrm{C}$ for several minutes. But upon illumination, degradation towards the degraded state sets in again.

In 2006, Herguth et al. discovered a third state of the BO-related defect which shows negligible recombination activity (like the annealed state), but is stable upon further illumination (Fig. 1). This state can be reached from the degraded state at elevated temperatures, e.g. $70-230^{\circ} \mathrm{C}$, and in the presence of excess charge carriers $\Delta \mathrm{n}$ in the c-Si bulk [7-10]. Regeneration kinetics also follows the Arrhenius law and is additionally dependent on $\Delta \mathrm{n}$, with higher $\Delta \mathrm{n}$ speeding up regeneration.

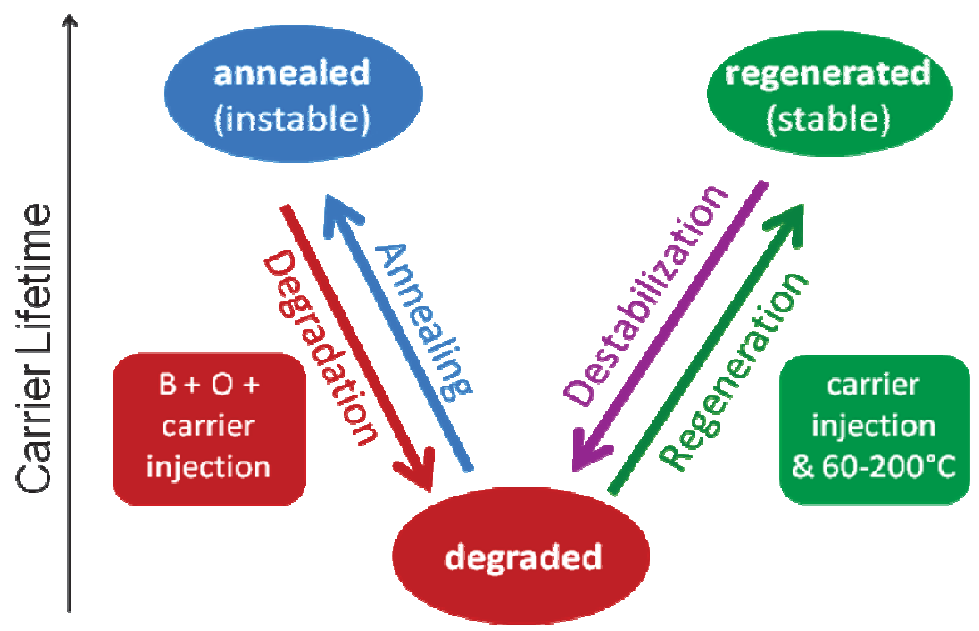

Fig. 1: 3-state model of the BO-related defect with respective reactions between different states. (after [7])

As regeneration kinetics is dependent on $\Delta \mathrm{n}$, regeneration time constants on solar cell level vary depending on biasing conditions. Highest $\Delta \mathrm{n}$ is reached at open circuit voltage $\left(\mathrm{V}_{\text {oc }}\right)$, whereas $\Delta \mathrm{n}$ is reduced at maximum power point (mpp) and has a minimum at short circuit current density $\left(\mathrm{j}_{\mathrm{sc}}\right)$ condition. This means that regeneration is faster at $\mathrm{V}_{\mathrm{oc}}$ compared to mpp or $\mathrm{j}_{\mathrm{sc}}$ condition $[8,9]$. On the other hand, a better surface passivation at the rear for the PERC technology leads to higher $\Delta \mathrm{n}$ in the cell compared to full Al BSF technology. Under the assumption of keeping the front side technology and bulk diffusion length constant, this should lead to faster regeneration for PERC-type solar cells [11].

\section{The Impact of Hydrogen for Regeneration Kinetics}

Regeneration is not observed when low pressure chemical vapor deposition (LPCVD) [12] or sputtering without hydrogen [13] instead of plasma-enhanced chemical vapor deposition (PECVD) is used for deposition of silicon nitride as surface passivation. Both techniques differ from PECVD by the fact that the resulting silicon nitride layers have negligible $\mathrm{H}$ concentration $[\mathrm{H}]$. Therefore, the firing step following after deposition does not lead to significant amounts of $\mathrm{H}$ being released into the c-Si bulk. This led to the assumption that $\mathrm{H}$ in the c-Si bulk might be a prerequisite for regeneration to occur.

In the following, a series of experiments was carried out to prove this hypothesis. The effect of barrier layers between $\mathrm{H}$-rich PECVD SiN $\mathrm{x}: \mathrm{H}$ and $\mathrm{c}-\mathrm{Si}$ and was checked by inserting $\mathrm{Al}_{2} \mathrm{O}_{3}$ layers of varying thickness (deposited by atomic layer deposition and allowing only very slow regeneration when used without a $\mathrm{SiN}_{\mathrm{X}}: \mathrm{H}$ capping layer) [14]. While an $8 \mathrm{~nm}$ thick $\mathrm{Al}_{2} \mathrm{O}_{3}$ layer does not slow 
down the regeneration process after a firing step, a $16 \mathrm{~nm}$ thick layer does. This can be explained by the reduced $\mathrm{H}$ diffusion from the $\mathrm{SiN}_{\mathrm{x}}: \mathrm{H}$ through the thicker $\mathrm{Al}_{2} \mathrm{O}_{3}$ layer. It was also observed, that a deposited PECVD SiN $\mathrm{x}_{\mathrm{x}} \mathrm{H}$ without following firing step to release large amounts of $\mathrm{H}$ into the c-Si bulk does not lead to a significant regeneration effect [14].

For time resolved measurements during regeneration on lifetime samples, effective lifetime $\tau_{\text {eff }}$ (including surface recombination as well) is normally measured directly after an annealing step without any BO-related defects in the degraded state (Fig. 1) and then several times during regeneration. Assuming Shockley-Read-Hall recombination to be the dominant process in the bulk, the measured $\tau_{\text {eff }}$ can be transformed into a normalized defect concentration $\mathrm{N}^{*}(\mathrm{t})$ via

$$
N^{*}(t)=\frac{1}{\tau_{e f f}(t)}-\frac{1}{\tau_{e f f, \text { annealed }}}
$$

because lifetime of a certain SRH recombination channel scales inversely to the defect density. A fit of the decaying $\mathrm{N}^{*}(\mathrm{t})$ during regeneration yields a characteristic regeneration time constant $\mathrm{t}_{0}$ or a regeneration rate $1 / t_{0}$ via

$$
N^{*}(t) \propto \exp \left(-t / t_{0}\right)
$$
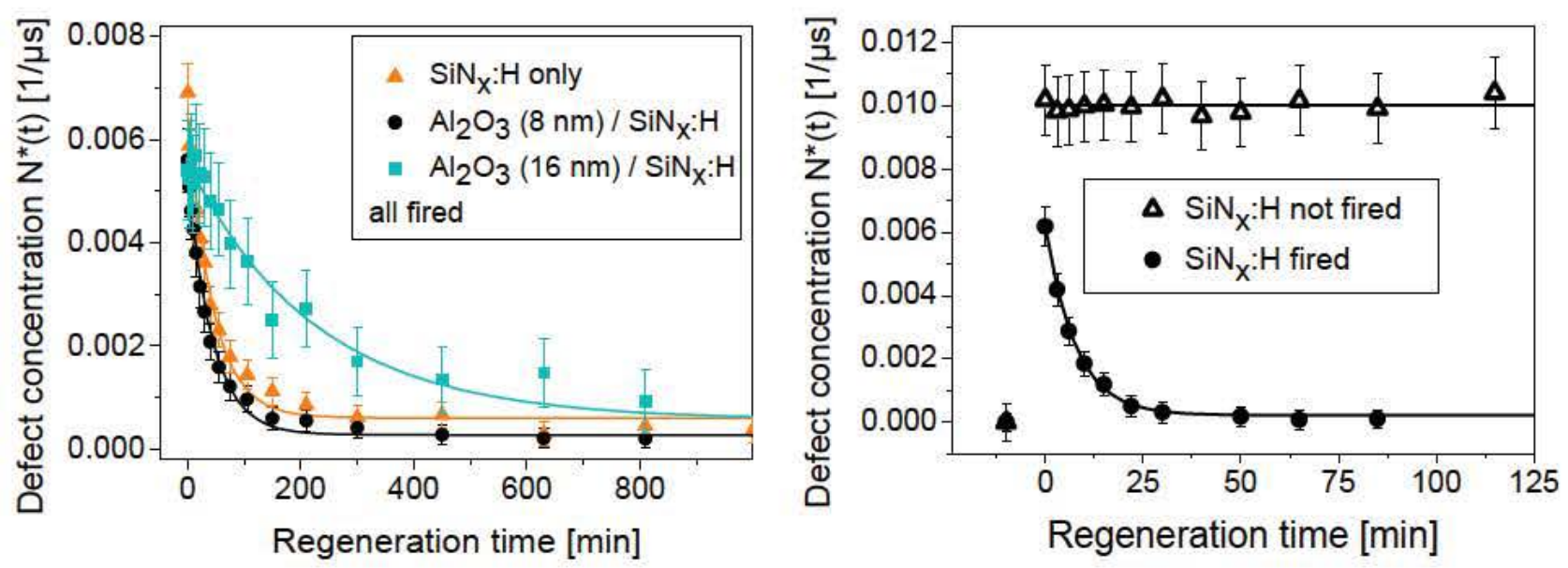

Fig. 2: Effect of $\mathrm{ALD} \mathrm{Al}_{2} \mathrm{O}_{3}$ layers of varying thickness as $\mathrm{H}$ diffusion barrier during firing on regeneration kinetics (left). Effect of firing of a PECVD $\mathrm{SiN}_{\mathrm{x}}: \mathrm{H}$ layer on regeneration kinetics (right). For both investigations normalized BO-related defect concentration after anneal (first data point) and during subsequent regeneration at $130^{\circ} \mathrm{C}$ and 0.6 suns illumination is given. (after [14])

In addition, another method for incorporation of $\mathrm{H}$ in the c-Si bulk was applied. Samples treated in a microwave-induced remote $\mathrm{H}$ plasma at temperatures $<250^{\circ} \mathrm{C}$ for incorporation of $\mathrm{H}$ led also to a significant regeneration, even without an additional firing step which in this case is not needed to diffuse $\mathrm{H}$ into the $\mathrm{c}-\mathrm{Si}$ bulk [15].

Impact of Hydrogen Concentration. If $\mathrm{H}$ is a prerequisite for regeneration to occur, then the question arises whether regeneration kinetics can be sped up with increasing $[\mathrm{H}]$. To check this, again a series of experiments was conducted by varying the PECVD $\mathrm{SiN}_{\mathrm{x}}: \mathrm{H}$ firing step in a conventional fast firing belt furnace $[16,17]$. Here a higher peak firing temperature leads to more $\mathrm{H}$ being released from the $\mathrm{SiN}_{\mathrm{x}}: \mathrm{H}$ layer into the $\mathrm{c}-\mathrm{Si}$ bulk and a faster regeneration. In addition the belt speed was varied, resulting in different temperature ramps during cool-down. For higher peak firing temperature, a fast cool-down speeds up the regeneration process, while for low peak firing 
temperatures $<700^{\circ} \mathrm{C}$ a fast cool-down does not accelerate regeneration (Fig. 3). This can be explained by a quenching effect of $\mathrm{H}$ : if temperature is high, $\mathrm{H}$ can effuse out of c-Si during cooldown faster than additional $\mathrm{H}$ can enter the c-Si bulk from the $\mathrm{SiN}_{\mathbf{x}}: \mathrm{H}$ source. This suggests that $[\mathrm{H}]$ in the c-Si bulk is another important parameter apart from temperature and $\Delta \mathrm{n}$ to describe and understand regeneration kinetics.
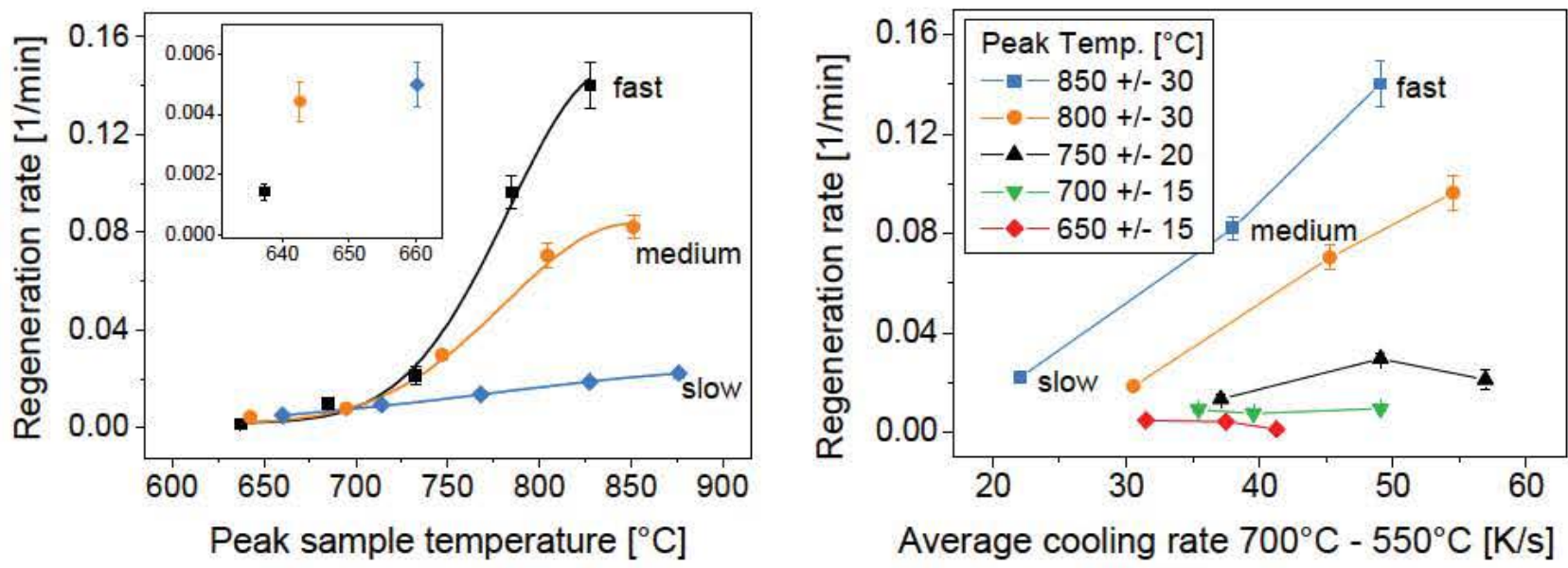

Fig. 3: Dependence of regeneration kinetics on peak firing temperature and belt speed (left). For peak firing temperatures $<700^{\circ} \mathrm{C}$, higher cooling rates do not lead to faster regeneration anymore. (after [17])

\section{Description of Defect Kinetics via Reaction Rates}

A very instructive model for explaining the observed kinetics during regeneration was published in 2010 based on the occurring transitions between the different states of the BO-related defect (Fig. 1) [18]. A set of linear differential equations describes the occupation of a respective state $n_{i}$ and the reaction towards or out of this specific state via reaction rates $\mathrm{k}_{\mathrm{ij}}$ with $\mathrm{i} j \mathrm{j}$. The respective reaction constants can be influenced by parameters like temperature, $\Delta \mathrm{n}$, or $[\mathrm{H}]$. An example for the change in occupation of the degraded state $B n_{B}$ can therefore be given as

$$
\frac{d n_{B}}{d t}=-\left(k_{B A}+k_{B C}\right) \cdot n_{B}+k_{A B} \cdot n_{A}+k_{C B} \cdot n_{C} .
$$

With this model, the behavior of recombination activity can be simulated. Under the assumptions that only reaction constants $\mathrm{k}_{\mathrm{AB}}$ (degradation) and $\mathrm{k}_{\mathrm{BC}}$ (regeneration) have values $>0$ and $\mathrm{k}_{\mathrm{AB}}=10 \mathrm{k}_{\mathrm{BC}}$, the resulting occupation of states in the course of time is shown in Fig. 4 (left). Starting after an annealing step (with all defects being in state A), the degraded state B is populated. Once there are defects available in state $B$, the regeneration reaction sets in and state $\mathrm{C}$ gets populated. As both states $\mathrm{A}$ and $\mathrm{C}$ show negligible recombination activity, the lifetime measurement will follow the line representing the sum of defects being in state $A$ and state $C$. In Fig. 4 (right) a lifetime measurement in the course of time during regeneration is shown ( 1 sun illumination at varying temperatures). The fit according to the model described above leads to excellent matching and therefore proves that the 3 -state model can describe the situation very well. 

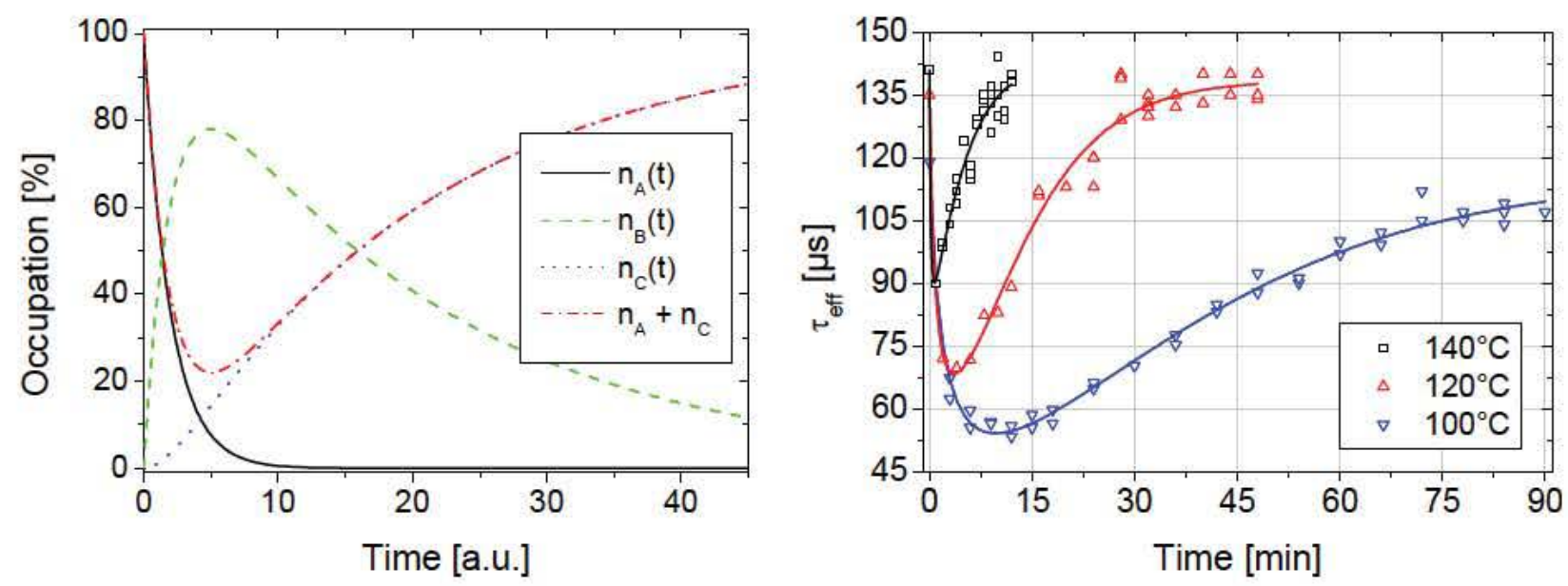

Fig. 4: Occupation of different states of the BO-related defect (Fig. 1) according to the model described in the text (left). The measured minority carrier lifetime values during regeneration of an annealed sample ( 1 sun at temperatures given in the graph) can be fitted very well according to the model assuming that both states $\mathrm{A}$ and $\mathrm{C}$ have negligible recombination activity (right). (after [18])

Effect of fast and slow Regeneration on long term Equilibrium of Defect States. All four reactions shown in Fig. 1 are thermally activated and of Arrhenius type, describing the probability of conversion $\mathrm{P}_{\text {conv }}$ from one state to another

$$
P_{\text {conv }}=v_{\text {char }} \cdot \exp \left(-\frac{E_{a}}{k_{B} T}\right) \text {, }
$$

with characteristic trial frequency $v_{\text {char }}$, activation energy $E_{a}$, Boltzmann constant $k_{B}$ and temperature $T$. While anneal and destabilization reaction rate depend only on $T$, the degradation reaction rate is influenced also by $\Delta \mathrm{n}$ (generated, e.g., by varying illumination intensity) up to illumination levels saturating for values $>0.01$ suns [6]. This means that for fixed values of $T$ and illumination levels $>0.01$ sun, degradation, anneal and destabilization reaction rates show fixed values, whereas regeneration reaction rate depends also strongly on specific values of $\Delta \mathrm{n}$ (adjusted, e.g., by illumination level) and $[\mathrm{H}]$. Table 1 gives an overview of values for $\mathrm{E}_{\mathrm{a}}$ and reaction rates for $\mathrm{T}=200^{\circ} \mathrm{C}$.

Table 1: Activation energies and reaction rates at $200^{\circ} \mathrm{C}$ and 1 sun illumination for reactions shown in Fig. 1. (values from [19-22])

\begin{tabular}{|l|l|l|}
\hline Reaction path & $\mathbf{E}_{\mathbf{a}}[\mathbf{e V}]$ & Time constants [min] \\
\hline Annealing & 1.3 & 0.25 \\
\hline Degradation & 0.4 & 0.03 \\
\hline Regeneration & 1.0 & varying \\
\hline Destabilization & 1.25 & 60 \\
\hline
\end{tabular}

As all four reactions shown in Fig. 1 are active in parallel, the ratio of the time constants determines the long term equilibrium values of occupancy for the three defect states. For a possible industrial application, a fast and complete regeneration process is desired. As regeneration is sped up by higher $T$, it is interesting to investigate whether $T$ can be increased independently of the specific sample with still all defects ending up in the regenerated state in long term equilibrium, or whether there is a peak $\mathrm{T}$ that should not be exceeded. At higher $\mathrm{T}$ the destabilization reaction starts to compete with regeneration, therefore the ratio between the time constants of regeneration and 
destabilization becomes important. If this ratio is $1 / 100$, almost all defects $(99 \%)$ can reach the regenerated state in long term equilibrium (Fig. 5, left). If this ratio is only $1 / 2$, then only $\sim 60 \%$ of the defects end up in the regenerated state, and also the annealed state stays populated (Fig. 5, right). As the only difference between the two scenarios shown in Fig. 5 is the time constant of regeneration ( $0.04 \mathrm{~min}$ vs. $33 \mathrm{~min}$, other time constants from Tab. 1$)$, it becomes clear that for a complete regeneration at high $\mathrm{T}\left(200^{\circ} \mathrm{C}\right.$ or above $)$ the sample has to have a short regeneration time constant.
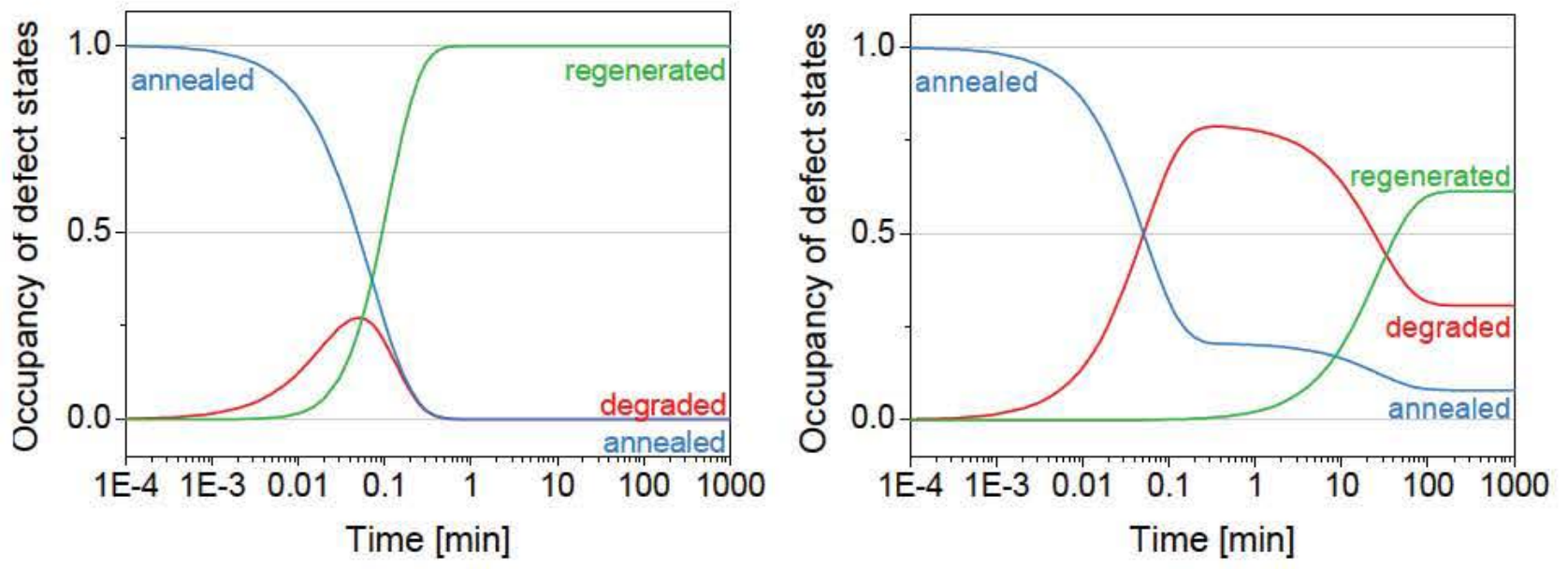

Fig. 5: Occupancy of BO-related defects with time under illumination (1 sun) at $200^{\circ} \mathrm{C}$, starting after annealing. For fast regenerating samples (assumed regeneration time constant: $0.04 \mathrm{~min}$ ) all defects end up in the regenerated $\mathrm{C}$ in long term equilibrium (left), while a regeneration time constant of 33 min leads to incomplete regeneration with a fraction of defects ending up in the (unstable) annealed state A (right). (after [19])

High Speed Regeneration. The regeneration time constant at a given $\mathrm{T}$ can be influenced by $\Delta \mathrm{n}$ and $[\mathrm{H}]$. This means that apart from adjusting illumination to speed up regeneration, the main parameter determining whether regeneration is complete at given $\mathrm{T}$ and $\Delta \mathrm{n}$ is the amount of $\mathrm{H}$ in the c-Si bulk present in the form needed for the regeneration reaction to occur [14]. The combination of chosen $\Delta \mathrm{n}$ and distribution of $\mathrm{H}$ therefore determines the peak $\mathrm{T}$ allowed for reaching complete regeneration.

Fig. 6 visualizes what this means in practice by plotting the completeness of regeneration in long term equilibrium in dependency of regeneration time constants with process temperature as parameter. For regeneration temperature of $200^{\circ} \mathrm{C}$ it can be concluded that a regeneration time constant $<1 \mathrm{~min}$ is needed to end up with almost all defects in the regenerated state $\mathrm{C}$, whereas a time constant of $\sim 50 \mathrm{~min}$ will lead only to $50 \%$ of the defects in the regenerated state. At $160^{\circ} \mathrm{C}$, a time constant of $50 \mathrm{~min}$ will lead to almost complete regeneration, and a time constant of $50 \mathrm{~min}$ at $130^{\circ} \mathrm{C}$ to complete regeneration. 


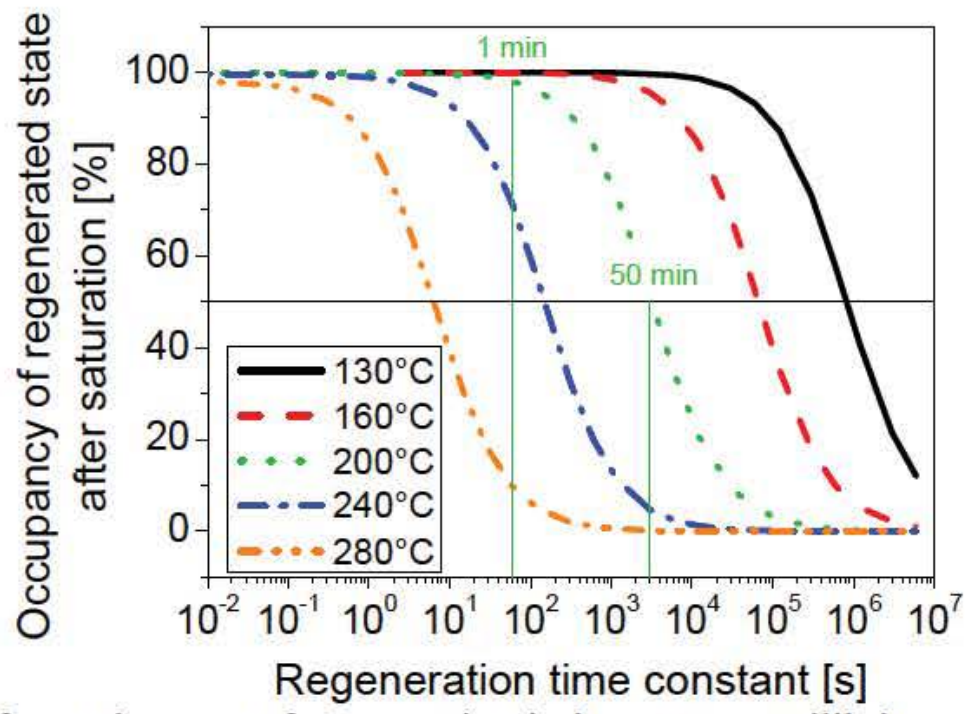

Fig. 6: Dependency of completeness of regeneration in long term equilibrium on regeneration time constants with $\mathrm{T}$ as parameter. (after [19])

For fast regenerating samples, regenerating temperature can be increased (with also illumination intensity being increased), so that regeneration time constants in the range of $1 \mathrm{~s}$ can be reached [14, $23,24]$. Generation of $\Delta \mathrm{n}$ is also possible via laser illumination leading to regeneration time constants $<1 \mathrm{~s}[26]$.

\section{Model of Regeneration}

A general model explaining the observed dependency of regeneration kinetics on $[\mathrm{H}]$ has been developed $[14,15]$. At temperatures $<100^{\circ} \mathrm{C}, \mathrm{H}$ is normally bound to impurities in c-Si (e.g. dopants or other impurities/defects) or to $\mathrm{H}$ forming molecular $\mathrm{H}$. Assuming that at least part of the $\mathrm{H}$ is bound in a configuration so that dissociation is enhanced under carrier injection, e.g., in BH-pairs with a dissociation energy being reduced to $1.1 \mathrm{eV}$ under injection conditions [14], this might explain the observed necessity for carrier injection for regeneration to occur and the activation energy for the regeneration reaction of $1.0 \mathrm{eV}$ (Table 1). Slow cool-down rates after peak firing temperature can result in less overall $[\mathrm{H}]$ in the c-Si bulk and to $\mathrm{H}$ being bound to other defects than B $[14,25]$, showing a more stable configuration with higher dissociation energy. This applies also to temperature steps around $100-400^{\circ} \mathrm{C}$ being carried out after cool-down as shown in [14, 25]. Therefore, the temperature history after peak firing (introduction of $\mathrm{H}$ into the c-Si bulk) determines the regeneration rate at given regeneration temperature and $\Delta \mathrm{n}$.

Depending on $\Delta \mathrm{n}$, the charge state of $\mathrm{H}$ can be changed in p-type c-Si material. E.g., upon illumination part of the normally positively charged $\mathrm{H}^{+}$can be present in the neutral state $\mathrm{H}^{0}$. The importance of the $\mathrm{H}$ charge state for mobility of $\mathrm{H}$ in c-Si and the possible bounding to and therefore passivation of defects like, e.g., the BO-related defect was highlighted recently by several authors $[24,26,27]$. In combination with the model presented in the paragraph above, this might explain the observed need for hydrogen, temperature and $\Delta \mathrm{n}$ for regeneration to occur.

Within the model also the observed dependency of regeneration rate on the amount of dopants, with higher dopant density leading to lower regeneration rates [28], can be explained at least qualitatively. The more dopants present in the c-Si bulk, the more $\mathrm{H}$ is trapped at these defect sites and the slower is the trap limited diffusion of $\mathrm{H}$ towards the BO-related defect. This behavior was also observed in compensated c-Si, where for compensation of the present $\mathrm{P}$ more $\mathrm{B}$ (and possibly also $\mathrm{Ga}$ ) is present, significantly increasing the overall p-type dopant concentration and slowing down regeneration rate despite of the same net doping concentration [19, 28-30]. A longer regeneration time constant then allows only lower regeneration temperatures at constant $\Delta \mathrm{n}$ for complete regeneration (see above) or leads to incomplete regeneration as observed experimentally [19]. 


\section{Summary}

The regeneration process of BO-related defects leads to a state of the defect that shows negligible recombination activity and no detectable degradation of lifetime upon further illumination at room temperature. This state can be reached by applying moderate temperatures in the presence of excess charge carriers and $\mathrm{H}$ in the c-Si sample.

The necessity of $\mathrm{H}$ in c-Si being released from, e.g., $\mathrm{SiN}_{\mathrm{x}}: \mathrm{H}$ layers during a high temperature firing step for a fast regeneration to occur could be shown by a series of experiments. It could also be shown that a higher concentration of $\mathrm{H}$ in the c-Si bulk leads to higher regeneration rates, provided that $\mathrm{H}$ is present in a form that allows a high mobility of atomic $\mathrm{H}$ under regeneration conditions.

A description of reactions between the different states of the BO-related defect via rate equations gives important insights in the kinetics of the defect transitions under specific experimental conditions and allows predictions for designing a process that leads to (almost) complete regeneration of a the BO-related defects. Apart from regeneration temperature, $\Delta \mathrm{n}$ and $[\mathrm{H}]$ in the cSi bulk of the sample to be regenerated play a crucial role.

Fast regenerating samples can be completely regenerated within seconds, provided that $\Delta \mathrm{n}$ is adapted at high regeneration temperature and $\mathrm{H}$ is present in sufficient concentration and suitable form.

A model describing the regeneration process was presented and is based on $\mathrm{H}$ being bound to a defect that allows dissociation at regeneration temperature and presence of excess charge carriers. An example is $\mathrm{H}$ being bound to $\mathrm{B}$, with activation energy of $1.1 \mathrm{eV}$ under illumination close to the one observed for regeneration $(1.0 \mathrm{eV})$. More traps for $\mathrm{H}$ in the c-Si bulk lead to lower mobility of $\mathrm{H}$ during regeneration and therefore slow down the regeneration process. This leads to incomplete regeneration if regeneration temperature is chosen too high.

\section{Acknowledgements}

Part of this work was funded by the German BMU under contracts 0325581 and $0325450 \mathrm{~A}$. The content is the responsibility of the authors.

\section{References}

[1] H. Fischer, W. Pschunder, Investigation of photon and thermal induced changes in silicon solar cells, in: Proc. $10^{\text {th }}$ IEEE PVSC, Palo Alto, USA, 1973, pp. 404-411.

[2] S.W. Glunz, S. Rein, W. Warta, J. Knobloch, W. Wettling, Degradation of carrier lifetime in Cz silicon solar cells, Sol. En. Mat. Sol. Cells 65 (2001) 219-229.

[3] J. Schmidt A. Cuevas, Electronic properties of light-induced recombination centers in borondoped Czochralski silicon, J. Appl. Phys. 86(6) (1999) 3175-3180.

[4] S. Rein, R. Falster, S.W. Glunz, S. Diez, Quantitative correlation of the metastable defect in Cz-silicon with different impurities, in: Proc. $3^{\text {rd }}$ WCPEC, Osaka, Japan, 2003, pp. 1048-1052.

[5] K. Bothe, R. Sinton, J. Schmidt, Fundamental boron-oxygen-related carrier lifetime limit in mono- and multicrystalline silicon, Prog. Photovolt.: Res. Appl. 13 (2005) 287-296.

[6] J. Schmidt, K. Bothe, Structure and transformation of the metastable boron- and oxygen-related defect center in crystalline silicon, Phys. Rev. B 69 (2004) 024107.

[7] A. Herguth, G. Schubert, M. Kaes, G. Hahn, A new approach to prevent the negative impact of the metastable defect in boron doped $\mathrm{Cz}$ silicon solar cells, In: Proc. $4^{\text {th }}$ WCPEC, Waikoloa, USA, 2006, pp. 940-943. 
[8] A. Herguth, G. Schubert, M. Kaes, G. Hahn, Avoiding boron-oxygen related degradation in highly boron doped $\mathrm{Cz}$ silicon, In: Proc. $21^{\text {st }}$ EC PVSEC, Dresden, Germany, 2006, pp. 530-537.

[9] A. Herguth, M. Kaes, G. Schubert, G. Hahn, Further investigations on the avoidance of boronoxygen related degradation by means of regeneration, In: Proc. $22^{\text {nd }}$ EC PVSEC, Milan, Italy, 2007, pp. 893-896.

[10]A. Herguth, G. Schubert, M. Kaes, G. Hahn, Investigations on the long time behavior of the metastable boron-oxygen complex in crystalline silicon, Progr. Photovolt.: Res. Appl. 16(2) (2008) 135-140.

[11]A. Herguth, R. Horbelt, S. Wilking, R. Job, G. Hahn, Comparison of BO Regeneration dynamics in PERC and Al-BSF solar cells: submitted to Energy Procedia 2015

[12] K.A. Münzer, Hydrogenated silicon nitride for regeneration of Light Induced Degradation, In: Proc. $24^{\text {th }}$ EUPVSEC, Hamburg, Germany, 2009, pp. 1558-1561.

[13]G. Krugel, W. Wolke, J. Geilker, S. Rein, R. Preu, Impact of hydrogen concentration on the regeneration of Light Induced Degradation, En. Proc. 8 (2011) 47-51.

[14] S. Wilking, C. Beckh, S. Ebert, A. Herguth, G. Hahn, Influence of bound hydrogen states on BO-regeneration kinetics and consequences for high-speed regeneration processes, Sol. En. Mat. Sol. Cells 131 (2014) 2-8.

[15] S. Wilking, A. Herguth, G. Hahn, Influence of hydrogen on the regeneration of boron-oxygen related defects in crystalline silicon, J. Appl. Phys. 113 (2013) 194503.

[16] S. Wilking, S. Ebert, A. Herguth, G. Hahn, Influence of short high temperature steps on the regeneration of boron-oxygen related defects, in: Proc. $28^{\text {th }}$ EU PVSEC, Paris, France, 2013, pp. 3438.

[17] S. Wilking, S. Ebert, A. Herguth, G. Hahn, Influence of hydrogen effusion from hydrogenated silicon nitride layers on the regeneration of boron-oxygen related defects in crystalline silicon, J. Appl. Phys. 114 (2013) 194512.

[18]A. Herguth, G. Hahn, Kinetics of the boron-oxygen related defect in theory and experiment, J. Appl. Phys. 108 (2010) 114509.

[19] S. Wilking, M. Forster, A. Herguth, G. Hahn, From simulation to experiment: understanding BO-regeneration kinetics: submitted to Sol. En. Mat. Sol. Cells (2015)

[20]J. Schmidt, K. Bothe, Structure and transformation of the metastable boron- and oxygen-related defect center in crystalline silicon, Phys. Rev. B 69 (2004) 024107.

[21]S. Rein, T. Rehrl, W. Warta, S.W. Glunz, G. Willeke, Electrical and thermal properties of the metastable defect in boron-doped Czochralski silicon (Cz-Si), in: Proc. $17^{\text {th }}$ EC PVSEC, Munich, Germany, 2001, pp. 1555-1560.

[22] S.W. Glunz, E. Schäffer, S. Rein, K. Bothe, J. Schmidt, Analysis of the defect activation in Cz silicon by temperature dependent bias-induced degradation of solar cells, in: Proc. $3^{\text {rd }}$ WCPEC, Osaka, Japan, 2003, pp. 919-922.

[23] S. Wilking, J. Engelhardt, S. Ebert, C. Beckh, A. Herguth, G. Hahn, High speed regeneration of BO-defects: improving long-term solar cell performance within seconds, In: Proc. $29^{\text {th }}$ EUPVSEC, Amsterdam, Netherlands, 2014. 
[24] B.J. Hallam, P.G. Hamer, S. Wang, L. Song, N. Nampalli, M.D. Abbott, C. Chan, D. Lu, A.M. Wenham, L. Mai, N. Borojevic, A. Li, D. Chen, M.Y. Kim, A. Azmi, S. Wenham, Advanced hydrogenation of dislocation clusters and boron-oxygen defects in silicon solar cells: submitted to En. Procedia (2015)

[25] S.A. McQuaid, M.J. Binns, R.C. Newman, E.C. Lightowlers, J.B. Clegg, Solubility of hydrogen in silicon at $1300^{\circ} \mathrm{C}$, Appl. Phys. Lett. 62 (14) (1993) 1612-1614.

[26]P. Hamer, B. Hallam, S. Wenham, M. Abbott, Manipulation of hydrogen charge states for passivation of p-type wafers in photovoltaics, IEEE J. Photovolt. 4 (2014) 1252-1260.

[27]C. Sun, F.E. Rougieux, and D. Macdonald, A unified approach to modelling the charge state of monatomic hydrogen and other defects in crystalline silicon, J. Appl. Phys. 117 (2015) 045702.

[28]S. Dubois, N. Enjalbert, J.P. Garandet, R. Monna, J. Kraiem, Light-Induced Degradation and Regeneration in compensated upgraded metallurgical silicon, in: Proc. $23^{\text {rd }}$ EU PVSEC, Valencia, Spain, 2008, pp. 1437-1440.

[29]B. Lim, A. Liu, D. Macdonald, K. Bothe, and J. Schmidt, Impact of dopant compensation on the deactivation of boron-oxygen recombination centers in crystalline silicon, Appl. Phys. Lett. 95 (2009) 232109.

[30]R. Sondena, A. Holt, A.K. Soiland, Electrical properties of compensated n- and p-type monocrystalline silicon, in: Proc. $26^{\text {th }}$ EUPVSEC, Hamburg, Germany, 2011, pp. 1824-1828. 